\title{
New insights into the chemistry of Coenzyme Q-0: A voltammetric and spectroscopic study
}

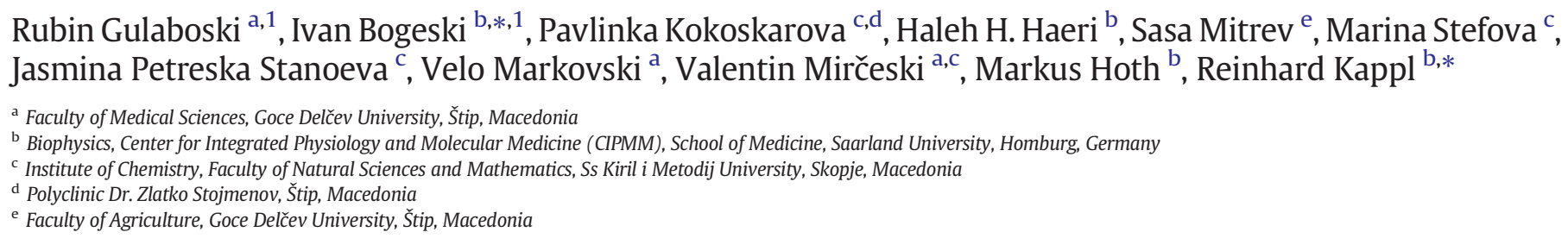

\section{A R T I C L E I N F O}

\section{Article history:}

Received 22 October 2015

Received in revised form 25 May 2016

Accepted 26 May 2016

Available online 29 May 2016

\section{Keywords:}

Coenzyme Q-0

Voltammetry

EPR

Hydroxyl benzoquinones

Antioxidants

Calcium binding

\begin{abstract}
A B S T R A C T
Coenzyme Q-0 (CoQ-0) is the only Coenzyme Q lacking an isoprenoid group on the quinoid ring, a feature important for its physico-chemical properties. Here, the redox behavior of CoQ-0 in buffered and non-buffered aqueous media was examined. In buffered aqueous media CoQ-0 redox chemistry can be described by a 2-electron-2-proton redox scheme, characteristic for all benzoquinones. In non-buffered media the number of electrons involved in the electrode reaction of CoQ- 0 is still 2; however, the number of protons involved varies between 0 and 2 . This results in two additional voltammetric signals, attributed to 2-electrons $-1 \mathrm{H}^{+}$and 2-electrons- $\mathrm{H}^{+}$redox processes, in which mono- and di-anionic compounds of $\mathrm{CoQ}-0$ are formed. In addition, CoQ-0 exhibits a complex chemistry in strong alkaline environment. The reaction of $\mathrm{CoQ}-0$ and $\mathrm{OH}^{-}$anions generates several hydroxyl derivatives as products. Their structures were identified with HPLC/MS. The prevailing radical reaction mechanism was analyzed by electron paramagnetic resonance spectroscopy. The hydroxyl derivatives of CoQ- 0 have a strong antioxidative potential and form stable complexes with $\mathrm{Ca}^{2+}$ ions. In summary, our results allow mechanistic insights into the redox properties of $\mathrm{CoQ}-0$ and its hydroxylated derivatives and provide hints on possible applications.
\end{abstract}

@ 2016 Elsevier B.V. All rights reserved.

\section{Introduction}

Quinones (Q) and hydroquinones (HQ) are members of a large class of organic compounds attracting general attention due to their physiological relevance for the respiratory chain, redox enzymes, ionic channels and many other cellular processes [1-3]. The broad range of their chemical reactions is driven by the large electronic density present in the conjugated cyclohexadienic or benzoic aromatic ring containing di-keto-diol groups. Indeed, the chemical reactivity and the functions of particular Q or HQ systems depend significantly on the nature and number of the substituents attached to the quinoid ring. Classification as toxins, drugs, antioxidants, redox mediators, biocatalysts, pigments etc., reflects the diversity of the functions of $\mathrm{Q}$ and $\mathrm{HQ}$. These systems are very interesting mainly because of their redox activity and are most probably the dominant redox active species within bioorganic compounds. The di-keto-diol moiety of $\mathrm{Q}$ and $\mathrm{HQ}$ is a quite suitable platform for exchanging electrons with many organic and inorganic

\footnotetext{
* Corresponding authors.

E-mail addresses: ivan.bogeski@uks.eu (I. Bogeski), reinhard.kappl@uks.eu (R. Kappl).

1 Contributed equally.
}

substrates. Due to the indispensable function in the processes of oxidative phosphorylation, Coenzyme Q-10 (CoQ-10) and its derivatives are the most prominent members in the family of $\mathrm{Q} / \mathrm{HQ}$ [4-7]. Although the number of studies related to the chemical and redox features of CoQ family members has increased tremendously in the last three decades [8-18], many key features are still not well understood. In our last two publications we have shown that Coenzyme Q-1 (CoQ-1) and CoQ-10 undergo structural changes in strong alkaline environment or in the presence of Cytochrome P450 enzymes [19,20]. As main reaction products we identified several hydroxy derivatives of CoQ- 1 and CoQ$10[19,20]$. The "isoprenoid Q and HQ" mainly function as electron and proton carriers [4-7], but it was not until recently that new properties of the hydroxy derivatives of CoQ- 1 and CoQ-10 were unraveled highlighting their potential for binding earth-alkaline cations and even facilitating their transfer across biomimetic membranes [19,20]. Moreover, due to their higher electronic density profiles, the novel hydroxy derivatives of CoQ-1 and CoQ-10 show much higher antioxidative potential compared to the hydroquinone forms of native CoQ-1 and CoQ-10. In the present work we focused on the chemistry and redox chemistry of the elementary member of the CoQ family, Coenzyme Q0 (CoQ-0) analyzing its redox chemistry in buffered and non-buffered 
aqueous solutions between $\mathrm{pH}=1$ and $\mathrm{pH}=10$ in detail, and we also studied its chemistry in strong alkaline media. We used EPR, HPLC, and UV-VIS together with voltammetric techniques to define the reaction mechanism of CoQ-0 in alkaline solution and to detect the derivatives obtained in that reaction. After re-titration to neutral $\mathrm{pH}$, we also investigated the metal-binding and antioxidative properties of the novel hydroxyl derivatives of CoQ- 0 . In contrast to the other CoQ species, CoQ-0 does not possess an isoprenyl group and is thus the smallest member of this family (see Schematic 1 ). The absence of the isoprenyl groups very likely affects its physico-chemical properties when compared with the other members.

The chemistry and in particular the redox chemistry of CoQ-0 have not been thoroughly examined in the past. Only few studies have been reported which consider the properties of CoQ- 0 as an electron acceptor of the superoxide radical or as a model for the quinone site in bacterial photosynthetic reaction center [21-23]. In addition to our previous studies on CoQ-1 and CoQ-10, the work presented here significantly contributes to a better understanding of the complex chemistry and redox properties of these biologically important organic compounds, and it also implies potential applications of its derivatives as cation chelators and antioxidants.

\section{Materials and methods}

If not otherwise stated, all chemicals were purchased from MERCK and used without further purification.

\subsection{Electrochemistry}

For performing electrochemical measurements with cyclic and square-wave voltammetric techniques, we used an AUTOLAB potentiostat model PGSTAT 12 (Eco-Chemie, The Netherlands), equipped with a conventional three-electrode setup. $\mathrm{An} \mathrm{Ag} / \mathrm{AgCl}$ electrode (filled with $3 \mathrm{M} \mathrm{KCl}$ ) was used as reference and a Pt wire as counter electrode. The working electrode was a glassy carbon type (Metrohm, Germany) with a diameter of $1.5 \mathrm{~mm}$ and was carefully cleaned before each experiment by polishing with aluminium oxide powder for $30 \mathrm{~s}$ and rinsing with de-ionized water. All voltammetric experiments were performed at room temperature. For each point presented in the diagrams, at least 6 consecutive voltammograms were recorded and averaged.

\subsection{UV - Vis- and electron paramagnetic resonance spectroscopy (EPR)}

Spectrophotometric experiments were carried out with a UV-VIS spectrophotometer Model Ultrospec 2110pro using the full range of wavelengths between 200 and $900 \mathrm{~nm}$.

EPR experiments were performed at room temperature with a Bruker spectrometer (ESP300e) equipped with a TMH cavity. The amplitude of the modulation signals was varied between 0.001 and

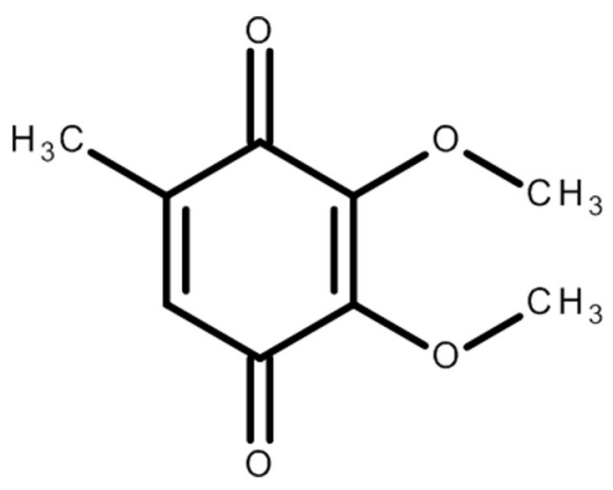

Schematic 1. Structural formula of Coenzyme Q-0.
$0.02 \mathrm{mT}$ depending on the sample. The microwave power was set to 0.2 or $0.63 \mathrm{~mW}$. Spectra were recorded with variable scan times up to $250 \mathrm{~s}$ and were consecutively stored in order to monitor the kinetic behavior of the radicals. The samples were prepared either at $\mathrm{pH}=12$ or $\mathrm{pH}=13$ in the presence or absence of oxygen (purging solutions with nitrogen), and were filled into a flat cell (Wilmad) under nitrogen atmosphere.

\subsection{HPLC/MS}

For the chromatographic experiments we used a XDB-C18 Zorbax column with dimensions $150 \times 4.6 \mathrm{~mm}$ ID, particle diameter $5 \mu \mathrm{m}$ (Agilent, U.S.). The mobile phase was a mixture of two solvents: water with formic acid $(1 \%, V / V)$ and methanol. A gradient was used beginning with $5 \%(V / V)$ methanol in the first $5 \mathrm{~min}$, reaching $10 \%$ at $10 \mathrm{~min}, 85 \%$ at $15 \mathrm{~min}$ and $100 \%$ methanol from 25 to $30 \mathrm{~min}$. The flow rate was $0.4 \mathrm{~mL} \mathrm{~min}^{-1}$, while the injection volume was $5 \mu \mathrm{L}$. The HPLC system was equipped with an Agilent 1100 series diode array detector (DAD) coupled to a mass spectrometer (Agilent Technologies, Waldbronn, Germany). It consists of a G1312A binary pump, a G1313A autosampler, a G1322A degasser, and a G1315B photodiode array detector, controlled by ChemStation software (Agilent, v.08.03). The spectral data of all peaks were collected at 190 and $600 \mathrm{~nm}$, while the chromatograms were recorded at $270 \mathrm{~nm}$. The mass detector was a G2445A ion-trap mass spectrometer equipped with electrospray ionization (ESI) system controlled by LCMSD software (Agilent, v.6.1.). Nitrogen was used as nebulizing gas at a pressure of $50 \mathrm{psi}$, and the flow was adjusted to $12 \mathrm{~L} \mathrm{~min}^{-1}$. The heated capillary temperature was $350{ }^{\circ} \mathrm{C}$, and the voltage was $4 \mathrm{kV}$. MS data were acquired in the positive ionization mode. The full scan mass covered the $\mathrm{m} / \mathrm{z}$ range from 15 to 500 . Collision-induced fragmentation experiments were performed in the ion trap using helium as a collision gas, with voltage ramping cycle from 0.3 to $2 \mathrm{~V}$. The maximum accumulation time of the ion trap and the number of MS repetitions to obtain the MS average spectra were set at $400 \mathrm{~ms}$ and 3, respectively.

\section{Results and discussion}

\subsection{Voltammetry of Coenzyme Q-0 in buffered water solution}

The redox features of many hydrophilic and lipophilic $\mathrm{Q}$ and HQ have been intensively studied by various electrochemical methods [4, $19,20,24-29]$, but surprisingly, there are only few reports related to the electrochemical features of the simplest CoQ member, i.e. CoQ-0 [21-23]. Because the water solubility of CoQ-0 (2,3-dimethoxy-5-methyl-p-benzoquinone) is very good (about $100 \mathrm{mg} / \mathrm{L}$ ), one can easily perform common voltammetry of CoQ-0 in aqueous solutions. In buffered acidic, neutral and slightly alkaline media, CoQ-0 has high chemical stability, and its redox chemistry can be described by the well-known twoelectron-two proton redox scheme. Cyclic voltammograms of $0.5 \mathrm{mM}$ CoQ-0 were recorded in buffered media with a pH ranging from 2 to 8 (compiled in Fig. S1). The corresponding square-wave voltammograms are shown in Fig. 1A. The electrode transformation of CoQ-0 in buffered water solutions is a diffusion-controlled process which is confirmed by the linear dependence of the peak currents (of both cathodic and anodic peaks) on the square root of the applied scan rates (see Fig. S1B). The slope (see Fig. S1C) allows to estimate the diffusion coefficient of CoQ0 molecules [30], which was determined as $D=4.40 \cdot 10^{-6} \mathrm{~cm}^{2} \mathrm{~s}^{-1}$. The cathodic-to-anodic peak separation in cyclic voltammograms (Fig. $\mathrm{S} 1 \mathrm{~A}$ ) of more than $400 \mathrm{mV}$ at scan rates higher than $50 \mathrm{mV} / \mathrm{s}$ is indicating that the redox process of CoQ- 0 in buffered media exhibits some kinetic hindrances, which are linked either to a slow electron transfer step or a slow protonation step.

Typically for quinone redox chemistry, the position of the voltammetric responses (i.e., the mid-peak potentials in $\mathrm{CV}$ or the net peak potential in SWV) is $\mathrm{pH}$ sensitive [3]. The dependence of the 

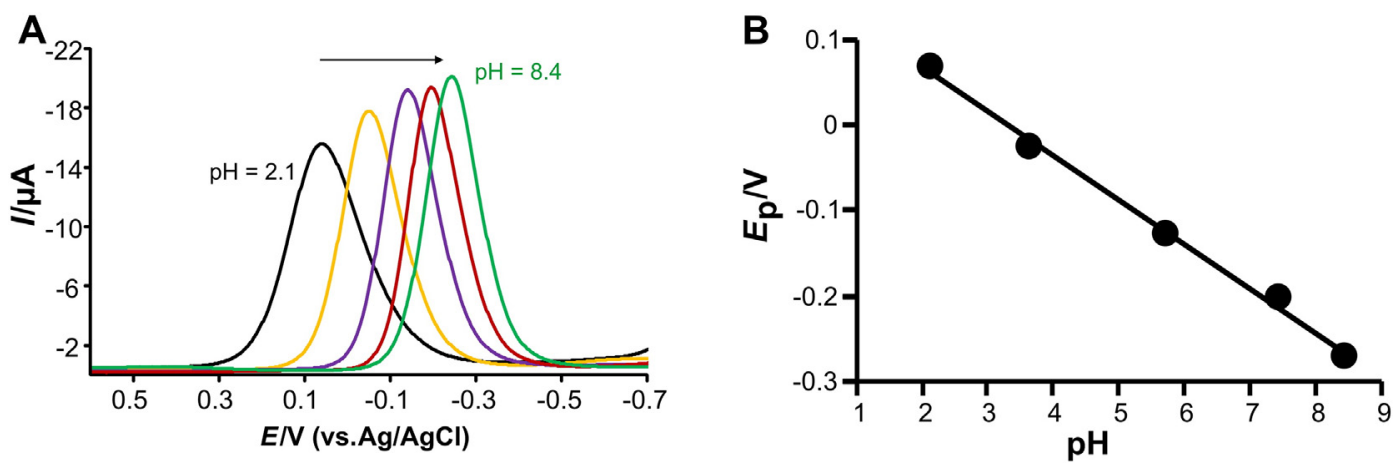

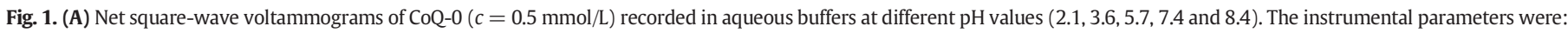

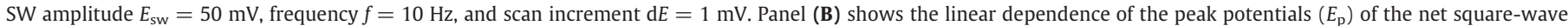
voltammograms as a function of $\mathrm{pH}$ with the regression equation: $E_{\mathrm{p}} / \mathrm{V}=-0.0576 \mathrm{pH}+0.1718\left(\mathrm{R}^{2}=0.996\right)$.

peak potentials $\left(E_{\mathrm{p}}\right)$ of the net $\mathrm{SW}$ voltammograms on $\mathrm{pH}$ is linear, with a slope of about $-60 \mathrm{mV} / \mathrm{pH}$ (Fig. 1B). Given that two electrons are exchanged between the working electrode and CoQ-0, the slope of $-60 \mathrm{mV}$ implies that two $\mathrm{H}^{+}$ions are also involved in the redox transformation of CoQ- 0 . In buffered media, the redox process of CoQ-0 can be presented by the reaction given in Schematic 2 .

Note that under such conditions, the CoQ-0 redox chemistry is sensitive to $\mathrm{H}^{+}$ions but not to other alkaline or earth-alkaline cations [20].

\subsection{Voltammetry of Coenzyme Q-0 in non-buffered water solution}

The voltammetry of CoQ-0 observed in non-buffered aqueous media is rather different compared to buffered water solutions. While in buffered aqueous media the electrode reaction of CoQ- 0 was portrayed in a single, chemically reversible voltammetric signal (see Fig. S1A), in nonbuffered water solutions, CoQ-0 exhibits more complex redox transformations. For a more detailed analysis of the CoQ-0 redox chemistry in non-buffered aqueous media, we recorded a series of voltammograms in several $\mathrm{pH}$ regions. From $\mathbf{p H}=\mathbf{1 . 0}$ to $\mathbf{p H}=\mathbf{2 . 0}$, a single chemically reversible and diffusion controlled voltammetric process of CoQ-0 exists that is sensitive to $\mathrm{pH}$. The slope of the linear dependence of the midpeak potentials of cyclic voltammograms, $E_{\text {mid,p }}$ vs. $\mathrm{pH}$, in this $\mathrm{pH}$ range is $-60 \mathrm{mV} / \mathrm{pH}$ (not shown). However, in the region from $\mathbf{p H}=\mathbf{2 . 4 0}$ to $\mathbf{p H}=\mathbf{3 . 7 0}$, the cyclic voltammograms show two distinct processes (Fig. 2A). The mid peak potential ( $\left.E_{\text {mid,pI }}\right)$ of the signal at more positive potentials (assigned as peak $\mathrm{I}^{\prime} \mathrm{I}^{\prime}$ ) is a linear function of $\mathrm{pH}$ with a slope of about $-58 \mathrm{mV} / \mathrm{pH}$ (Fig. 2B). The second signal positioned at more negative potentials (assigned as peak II-II') also shifts in negative direction with increasing $\mathrm{pH}$, but the slope of the $E_{\text {mid,pII }}$ Vs. $\mathrm{pH}$ dependence for this signal is reduced to $-31 \mathrm{mV} / \mathrm{pH}$ (Fig. 2B). These different slope values imply that a different number of $\mathrm{H}^{+}$ions is involved in the electrochemical transformations related to the processes of peak I-I' and peak II-II'. A quite interesting situation was observed for cyclic voltammograms recorded in the $\mathrm{pH}$ region between $\mathbf{p H}=\mathbf{3 . 7 5}$ and $\mathbf{p H}=\mathbf{4 . 6 0}$. In the very narrow $\mathrm{pH}$ range between $3.75<\mathrm{pH}<3.85$, the intensity of the second signal (peak II-II') decreases during the slight increase of $\mathrm{pH}$, and a new voltammetric signal appears between peak I-I' and peak II-II' (assigned as peak III-III') (see last two voltammograms in Fig. S2A). The intensity of peak III increases with increasing $\mathrm{pH}$, until, at $\mathrm{pH}=3.85$, the only signals remaining in the cyclic voltammograms are those of peak I-I ' and peak III-III' (Fig. S2A).

By further increasing the $\mathrm{pH}$ from 3.85 to 4.60 , the amplitude of the peak III-III' increases further, while the intensity of the peak I-I' decreases concomitantly (Fig. $2 \mathrm{C}$ ). Above $\mathrm{pH}=5.00$, the signal of the peak I-I' disappears completely, and the only signal in the cyclic voltammograms is that of peak III-III' (see Fig. S2B). The intensity of this signal (peak III-III') is virtually constant in the $\mathrm{pH}$ region from 5.50 to 10 (Fig. $\mathrm{S} 2 \mathrm{~B}$ ). Interestingly, the position of the signal III-III' is not affected by $\mathrm{pH}$ with a mid-peak potential of $-0.306 \mathrm{~V}$ between $\mathrm{pH}=3.80$ up to $\mathrm{pH}=$ 10.00. This independence of $E_{\text {mid,p3 }}$ of peak III-III' on pH implies that no protons are involved in the corresponding redox transformation in Fig. 2C. Similarly as observed in buffered media, all three signals of CoQ-0 recorded in non-buffered aqueous solutions show no sensitivity to alkaline and earth-alkaline cations (not shown).

\subsection{Mechanism of redox transformation of CoQ-0 in non-buffered aqueous solutions}

Comparing UV-VIS spectra of CoQ-0 recorded in buffered and nonbuffered aqueous media at different $\mathrm{pH}$ values (Fig. S3) shows a very good chemical stability up to $\mathrm{pH}=10$. Therefore, the features of the voltammetric responses of CoQ-0 observed in non-buffered media, as described in Fig. 2, should be related to the chemical properties of the products obtained by the electrochemical reduction of the native CoQ0 at the working electrode. As recently shown by Quan et al. [27], this specific behavior of quinone systems in non-buffered aqueous media depends mainly on the concentration ratio $\mathrm{Q} / \mathrm{H}^{+}$ions in the electrochemical cell. It was shown that a single signal exists in the cyclovoltammetric responses when the concentration $c\left(\mathrm{H}^{+}\right)$in the cell is much higher than the initial concentration of $\mathrm{Q}, c_{\mathrm{o}}(\mathrm{Q})$. Under such<smiles>COC1=C(OC)C(=O)C(C)=CC1=O</smiles><smiles>COc1c(O)cc(C)c(O)c1OC</smiles>

Schematic 2. Redox transformation of Coenzyme Q-0 in buffered aqueous media with pH from 2.0 to 8.5 . 

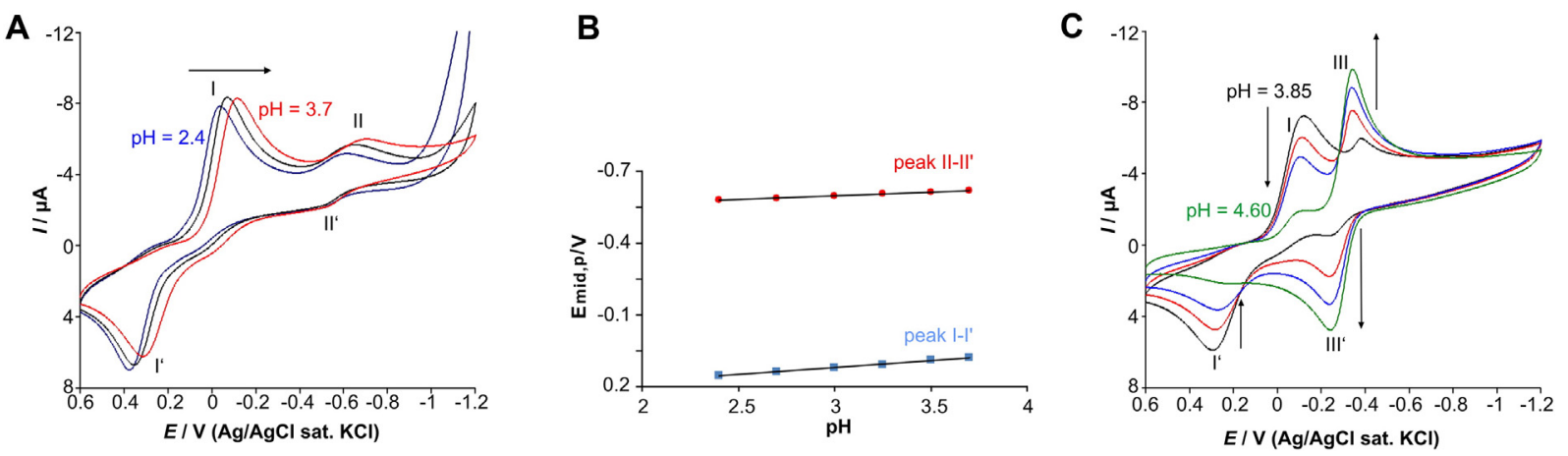

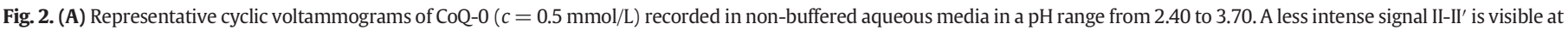

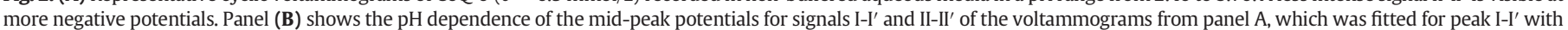

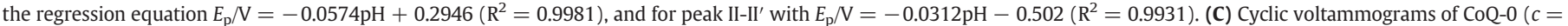

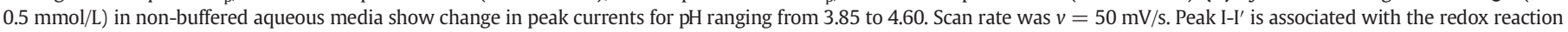

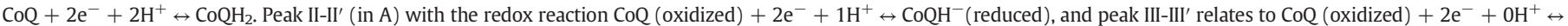
$\mathrm{CoQ}^{2-}$ (reduced).

conditions, the redox process of $\mathrm{Q}$ can be described by the well-known 2-electron- $2 \mathrm{H}^{+}$redox scheme, a situation corresponding to the features of the peak I-I' recorded in $\mathrm{pH}$ from 1.0 to 2.0. In case $c\left(\mathrm{H}^{+}\right)$becomes comparable to the concentration of CoQ-0 (i.e. for $2.2<\mathrm{pH}<4.8$ ), a second signal appears at a more negative potential and is associated to a 2-electron- $1 \mathrm{H}^{+}$process. This situation corresponds to the signal II-II' in Fig. 2A. If $c_{\mathrm{o}}(\mathrm{Q})$ is approximately one or more orders of magnitude higher than $c\left(\mathrm{H}^{+}\right)$, a third $\mathrm{pH}$-insensitive signal is observed, which can be described by 2 electrons- $0 \mathrm{H}^{+}$redox process, and corresponds to the features of the signal III-III' in Fig. $2 \mathrm{C}$ and Fig. S2B. The electrode process of CoQ-0 in non-buffered aqueous media, which are shown in Fig. 2, can be described for these three situations by the redox reactions:

Emid,p vs. $\mathrm{pH}$ dependence is $-60 \mathrm{mV} / \mathrm{pH}$ for $c o(\mathrm{CoQ}-0)<c(\mathrm{H}+)$.

$\mathrm{CoQ}+2 \mathrm{e}^{-}+2 \mathrm{H}^{+} \leftrightarrow \mathrm{CoQH}_{2}$

Emid,p vs. pH dependence is $-30 \mathrm{mV} / \mathrm{pH}$ for $\mathrm{co}(\mathrm{CoQ}-0) \sim c(\mathrm{H}+)$.

$\mathrm{CoQ}($ oxidized $)+2 \mathrm{e}^{-}+1 \mathrm{H}^{+} \leftrightarrow$ reduced $\mathrm{CoQH}^{-}\left(\mathrm{H}_{2} \mathrm{O}\right)_{\mathrm{n}}$

Emid,p vs. $\mathrm{pH}$ dependence is $0 \mathrm{mV} / \mathrm{pH}$ for $c o(\mathrm{CoQ}-0)>c(\mathrm{H}+)$.

$\mathrm{CoQ}($ oxidized $)+2 \mathrm{e}^{-}+0 \mathrm{H}^{+} \leftrightarrow$ reduced $\mathrm{CoQ}^{2-}\left(\mathrm{H}_{2} \mathrm{O}\right)_{\mathrm{m}}$

From Eqs. (1)-(3), it is obvious that the reaction products of processes II-II' and III-III', are present as mono-anionic or di-anionic forms. It appears that under such conditions the water dissociation process cannot quickly re-supply protons to balance the charge of the electrochemically created CoQ-0 anionic products in non-buffered aqueous media. As described in $[19,20,27]$, the stabilization of the electrode reaction products of redox reactions 2) and 3) can be achieved by hydrogen bonding with water molecules. Alternatively, the observed behavior of $\mathrm{Q}$ could be partially explained via a radical reaction mechanism [2426]. However, from the stability of the cyclic voltammograms obtained by consecutive cycling we conclude that no radical reaction mechanism takes place under such conditions. Moreover, the scan rate analysis clearly indicates that no preceding or follow-up chemical reaction is relevant for generating signals II-II' and III-III' in the voltammograms of Fig. 2. Therefore, we propose the redox reactions (1-3) as the most reasonable explanation for the observed redox chemistry of CoQ-0 in non-buffered aqueous media with $\mathrm{pH}$ ranging from 1 to 10 . It is important to stress that the voltammetric signal III-III' of CoQ-0 in non-buffered aqueous media shows almost electrochemically reversible behavior (see Fig. S4). Since no protonation takes place during this redox process, we conclude that the kinetic hindrances present in the $2 \mathrm{e}^{-}-2 \mathrm{H}^{+}$redox process of CoQ-0 in buffered media (Fig. 1 ) are due to a slow protonation step.

\subsection{Chemistry of Coenzyme Q-0 in alkaline media}

Recently we have shown that fully substituted CoQ family members (i.e. CoQ-1 and CoQ-10), but also some non-fully substituted dimethoxy benzoquinones (BQ) undergo structural changes in strong alkaline media $[19,20]$. One or both methoxy $\left(\mathrm{O}-\mathrm{CH}_{3}\right)$ groups of the CoQ-1 or CoQ-10 structure are replaced by one or two $\mathrm{OH}$ groups giving mainly mono- and di-hydroxy CoQ derivatives as products. CoQ-0 still retains three of the functional groups also present in the structures of CoQ-1 and CoQ-10 (i.e. the two methoxy groups and one methyl group), but is lacking the isoprenyl chain (see Schematic 1). From a mechanistic point of view, it is interesting to compare hydroxylation reactions of fully substituted CoQ with those of partly substituted CoQ-0 in alkaline solution. When dissolved in acidic, neutral and slightly alkaline media, the solution of CoQ-0 is yellow (Fig. S5 left). After increasing the $\mathrm{pH}$ above 10.5 , the solution turns red with intensity increasing over time. Upon titration of the reacted CoQ-0 solution to neutral $\mathrm{pH}$, the color of the solution remains red (Fig. S5 right). In cyclic voltammograms of $1 \mathrm{mmol} / \mathrm{L}$ CoQ-0, recorded after different reaction times in alkaline media at $\mathrm{pH}=13$ (Fig. S6), another signal appears at more negative potentials (assigned as IV-IV') in addition to the signal III-III' that originates from the native CoQ-0 (compare Fig. 2C). While the intensity of the signal III-III' decreases with time, the signal IV-IV' concomitantly increases and is the main signal after $240 \mathrm{~min}$.

Fig. $3 \mathrm{~A}$ compares the cyclic voltammograms of CoQ-0 recorded directly in $\mathrm{pH}=7$ (black trace) with that of CoQ-0 that reacted with $0.1 \mathrm{M} \mathrm{NaOH}$ for $45 \mathrm{~min}$ and was subsequently re-titrated to $\mathrm{pH}=7$ (red trace). Obviously, in the latter case, a major part of the native CoQ- 0 has been converted to another form(s) at potentials around $-0.620 \mathrm{~V}$. To obtain the structures of the products produced in this reaction, we performed HPLC/DAD/MS ${ }^{2}$ (High Performance Liquid Chromatography with Diode Array Detector experiments/Tandem Mass Spectrometry) using $1 \mathrm{mmol} / \mathrm{L}$ CoQ- 0 reacted in $\mathrm{pH}=13$ for $1 \mathrm{~h}$ and re-titrated to neutral $\mathrm{pH}$. The HPLC/DAD chromatogram obtained for this mixture is shown in Fig. 3B. The retention times, UV absorption 
A

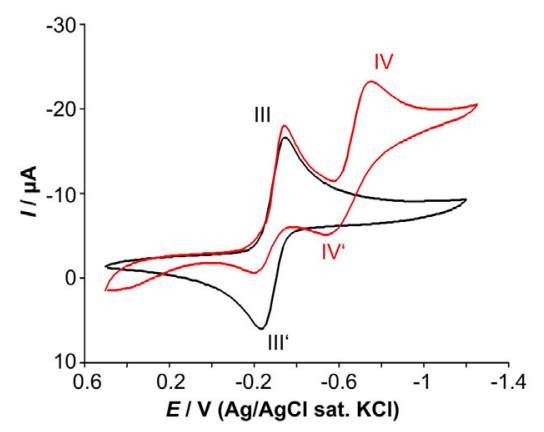

B

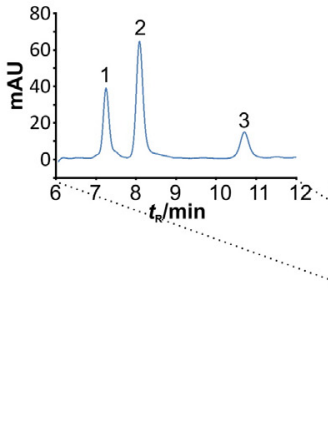

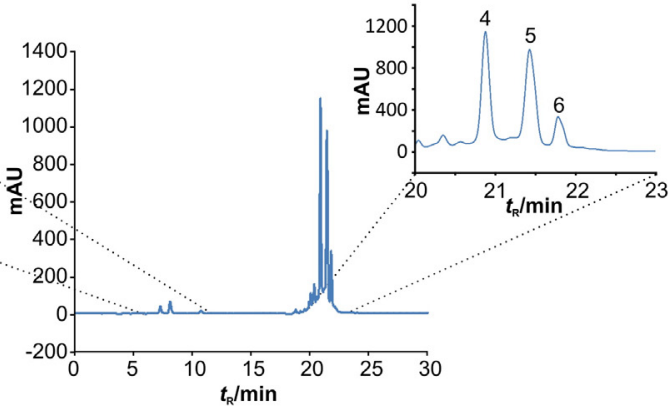

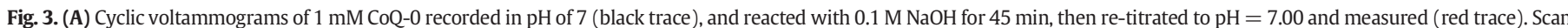

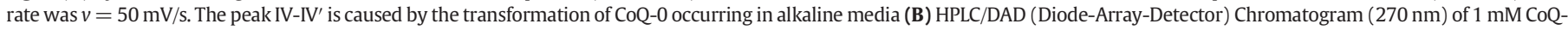

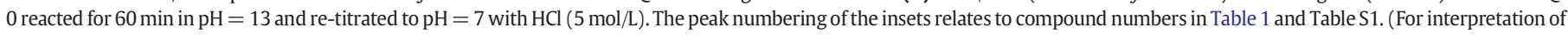
the references to color in this figure legend, the reader is referred to the web version of this article.)

maxima, the molecular weights and MS data of the compounds detected in HPLC/DAD/MS ${ }^{2}$ are given in Table S1. Considering the lipophilicity of the detected compounds (characterized by their retention times in Table S1) and the molecular weights, we suggest the structural formula of the compounds "1", " 2 ", " 4 ", “ 5 " and " 6 " given in Table 1 . For compound " 3 " we were not able to suggest a reasonable structure.

Compound 1 is a 6-hydroxy-CoQ-0 derivative in its reduced form, in which one OH-group has been substituted at position 6 of the reduced CoQ-0 structure. A common finding for three other products $(2,4$ and 6 ) is that at least one methoxy group is cleaved from their structures. Compound 2 is a di-hydroxy derivative of CoQ- 0 . In this compound, position 6 in the native CoQ-0 structure is substituted by one OH-group, but also one methoxy group is cleaved and substituted with $\mathrm{OH}$. Compound 4 is a mono-hydroxy derivative of $\mathrm{CoQ}-0$, in which one $\mathrm{O}-\mathrm{CH}_{3}$ group has been replaced by one $\mathrm{OH}$-group. Compound 6 is a dimer obtained by combining two CoQ-0 monomers in which both methoxy groups are substituted by $\mathrm{OH}$-groups. Such dimers are always present when a relatively high amount of 2,3-dihydroxy CoQ-derivatives is created. This happens either when CoQ-0 is dissolved in very strong alkaline media $(\mathrm{pH}>12.5)$, or when reaction times are very long (over $1 \mathrm{~h})[19]$.
In our recent publications, we have demonstrated that the conversion of methoxy-substituted BQ and some CoQ-family members in alkaline media is associated with complex radical reactions $[19,20]$. The mechanism of the reactions of CoQ-0 in alkaline media was deduced from electron paramagnetic resonance (EPR) experiments. When dissolving CoQ-0 in water at $\mathrm{pH}=7.8$ no spontaneous radical formation was detected over prolonged time. In order to characterize the oneelectron reduced CoQ-0 radical species, a twofold excess of $\mathrm{NaBH}_{4}$ was added to the aqueous solution, and, for optimal spectral resolution, spectral broadening was minimized using degassed deuterated water. The latter produces a highly resolved spectrum for the radical state of CoQ-0 (called P) which is dominated by the splitting of the three protons of the methyl-group (position 5, $0.244 \mathrm{mT}$ quartet) and the proton at position 6 (0.1943 mT, doublet) as derived from simulations (Fig. 4A). The more remote protons of both methoxy-groups contribute to the hyperfine pattern as indicated in the inset of panel 4A (with 0.0042 and $0.0015 \mathrm{mT})$ together with a single deuteron $(0.0043 \mathrm{mT})$ yielding a good spectral fit. In non-deuterated solution, the small couplings are hardly resolved but contribute to an increased line width ( 0.025 vs. $0.012 \mathrm{mT}$, Fig. 4B). Immediately after exposure to $0.1 \mathrm{M} \mathrm{NaOH}$ solution $(\mathrm{pH}=13)$ the one-electron reduced CoQ-0 signal $\mathrm{P}$ is present together

Table 1

Assignment of compounds identified by HPLC-mass spectrometry.

Compound $^{\mathrm{a}}(\mathrm{MW} / \mathrm{Da}) \quad$ Assignment $\quad$ Structural formula

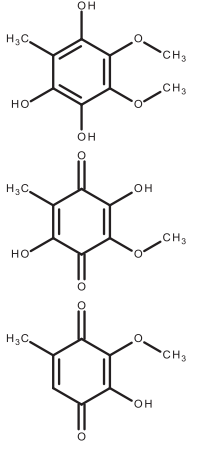<smiles>COC1=C(OC)C(=O)C(OC)C(=O)C1</smiles><smiles></smiles> 
A
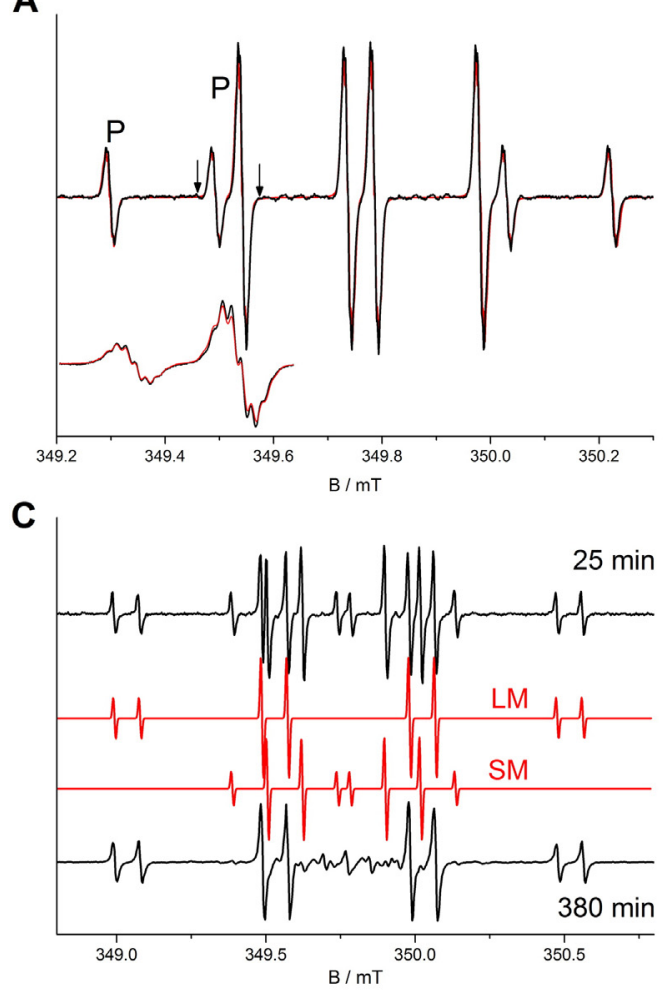

B

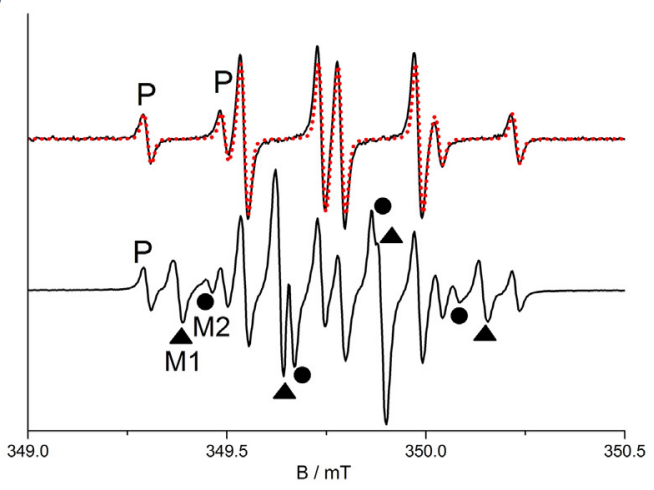

D

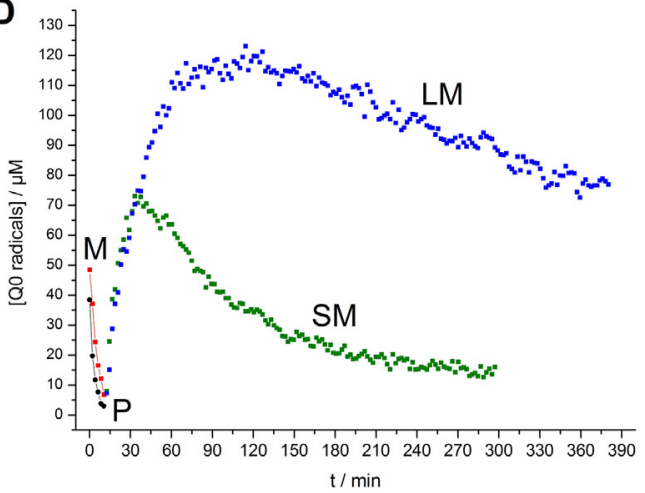

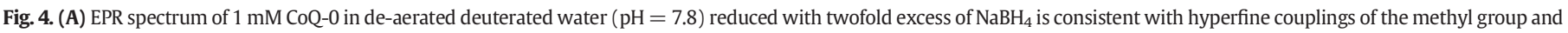

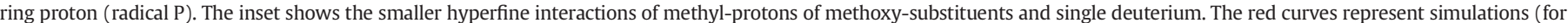

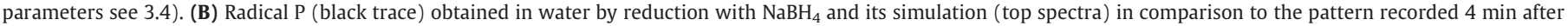

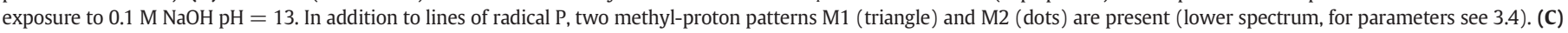

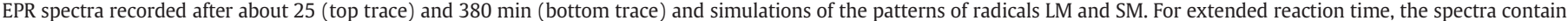

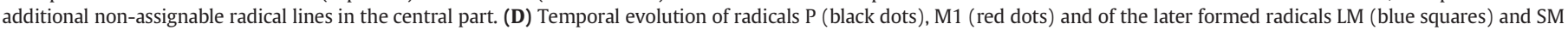

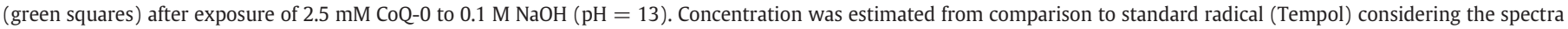
multiplicity. (For interpretation of the references to color in this figure legend, the reader is referred to the web version of this article.)

with two different quartet lines (M1, M2) typical for methyl-protons (Fig. 4B, marked with symbols) with slightly different couplings for M1 (0.0207 mT) and M2 (0.0255 mT) as well as different intensities. These species gradually lose intensity being replaced by two new signal giving species (LM and SM), which both are shown by simulation to consist of a methyl-coupling and a single proton coupling (Fig. 4C LM: $\mathrm{CH}_{3} 0.495 \mathrm{mT}, \mathrm{H} 0.085 \mathrm{mT}$; SM: $\mathrm{CH}_{3} 0.118, \mathrm{H} 0.394 \mathrm{mT}$ ). One of the signals (SM) decays slowly within $200 \mathrm{~min}$ while the other (LM) is quite persistent with large intensities for up to $400 \mathrm{~min}$, which is visualized in the kinetic diagram of Fig. 4D.

This kinetic behavior of radicals LM and SM is characteristic for a sequential mechanism of formation and decay, which was also found for model benzoquinone [20]. The well resolved resonances of SM and LM are accompanied by a multiplet of rather small central lines, which cannot be clearly assigned to interaction patterns for further identification (Fig. 4C). Additional experiments performed at $\mathrm{pH}=12$ and $\mathrm{pH}=14$ indicate that the mode of reaction is strongly pH-dependent (data not shown). For $\mathrm{pH}=12$ only signal $\mathrm{P}$ and $\mathrm{M} 1$ are observable over a time span of 400 min, whereas for $\mathrm{pH}=14$ signals P, M1 and M2 do not appear but rather species SM and LM are formed together with some minor components different to the $\mathrm{pH}=13$ experiment. From the EPR patterns observed at $\mathrm{pH}=13$, several aspects of radical mechanisms and the types of possible diamagnetic products can be derived. In a first step, the proton in position 6 is substituted by a hydroxyl group. This species easily deprotonates and transfers an electron to CoQ-0 forming radical P, the radical form of compound 5 of MS assignments. Analogous radical reaction pathways were found for the model substance 2,5-dimethoxy-1,4-benzoquinone in alkaline solution [20]. Due to loss of the ring proton, radicals $M$ are dominated by the methyl-proton quartet pattern with the characteristic 1:3:3:1 intensity ratio, which eventually produces the mono-hydroxylated compound 1 (Table 1) after further reduction, probably in a disproportionation reaction. Radicals M may also be associated to the one electron reduced compound 2, which in EPR should mainly show up as a methyl-proton pattern because the methoxy- and hydroxyl-protons give very small couplings as seen from the experiments at $\mathrm{pH}=7.8$ or, respectively, are absent in alkaline conditions. The radical species LM and SM formed later in the time course definitely show the methyl- and ring-proton couplings which indicates that for these species methoxy groups are attacked by $\mathrm{OH}^{-}$. Although not explicitly verifiable, the LM and SM species possibly refer to hydroxylation of ring positions 2 or 3 reflecting the asymmetry of the molecule as different coupling parameters. Because radical LM is much more stable than SM, it appears plausible to assign it to compound 4 found in mass spectra. SM on the other hand, could lose the second methoxy-group and form the 2,3-dihydroxy derivative which is not sufficiently stable and transforms to dimeric compound 6 in a condensation process. It is also mentioned that at $\mathrm{pH}=13$ and 14 , further, not assignable radicals of low intensity or transient appearance are observed by EPR. These might be precursors of products monitored in peak 3 and in the small signals of the HPLC trace (Fig. 3B). They may include compound 2 type radicals but also structures with multiple hydroxylations which may undergo ring opening reactions yielding instable radicals and finally chain products.

\subsection{Complexation chemistry of the hydroxyl derivatives of Coenzyme Q-0}

The presence of proton-donating $\mathrm{OH}$ groups in the structure of compounds 1, 2 and 4 from Table 1 significantly increases the electron 
density of these CoQ-0 hydroxyl derivatives. This, in turn, suggests that they should have a pronounced ability to form complexes with some cations. In a previous publications we have shown that the OH-derivatives of CoQ-1 and CoQ-10 [19], as well as some other hydroxyl BQ obtained from methoxy BQ [20] were able to form stable complexes with $\mathrm{Ca}^{2+}$ and other earth-alkaline cations. The ability to form such complexes is also confirmed for some of the hydroxyl CoQ-0 derivatives as demonstrated in Fig. 5A, where a square wave voltammogram of CoQ0 dissolved in $\mathrm{pH}=13$ for $45 \mathrm{~min}$ and subsequently re-titrated to $\mathrm{pH}=7$ in the absence of $\mathrm{Ca}^{2+}$ is shown (red trace). Further square wave voltammograms were recorded after addition of different concentration of $\mathrm{Ca}^{2+}$ ions in the measuring bath solution (all other traces). The native CoQ- 0 is insensitive to the concentration of $\mathrm{Ca}^{2+}$ ions (peak III-III') confirming our previous observations with CoQ-1 and CoQ-10, whereas peak IV-IV' at more negative potentials (which originates from some of the hydroxyl CoQ-0 derivatives) shifts by about $+60 \mathrm{mV}$ in positive direction per tenfold increase of the $\mathrm{Ca}^{2+}$ concentration (Fig. 5B). A positive slope of the dependence $E_{\mathrm{p}} \mathrm{Vs} . \log \left[\mathrm{Ca}^{2+}\right]$ indicates that the product of the electrochemical reduction of hydroxyl CoQ-0 derivative(s) forms complexes with $\mathrm{Ca}^{2+}$ ions $[19,20]$.

Considering that 2 electrons are involved in the redox reaction of $\mathrm{Q}$ in neutral media, the slope of the function $E_{\mathrm{p}} \mathrm{vs} . \log \left[\mathrm{Ca}^{2+}\right]$ of about $+60 \mathrm{mV}$ implies that two $\mathrm{Ca}^{2+}$ ions are involved in the complexation reaction with one molecule of $\mathrm{OH}-\mathrm{CoQ}-0$. Such a scenario is possible with derivative " 2 " from Table 1, i.e. 3,6-dihydroxy-2-methoxy-5-methyl-benzoquinone. Although mono-hydroxy derivatives of CoQ-0 should be present in the solution, we found no voltammetric signal of those derivatives in the potential region scanned. Correspondingly, the complexation process of the di-hydroxyl CoQ-0 derivative (di-OH-CoQ) with $\mathrm{Ca}^{2+}$ ions can be described by the following model (4):

$$
\begin{aligned}
& \text { di-OH-CoQ } \leftrightarrow \mathrm{CoQ}^{2-}(\text { oxidized })+2 \mathrm{e}^{-} \leftrightarrow \mathrm{CoQ}^{4-} \text { (reduced) } \\
& \quad+2 \mathrm{Ca}^{2+} \leftrightarrow \mathrm{Ca}^{2+}-\mathrm{CoQ}^{4-}-\mathrm{Ca}^{2+} .
\end{aligned}
$$

In a first step in Eq. (4), the di-OH-CoQ deprotonates in water creating double negatively charged $\mathrm{CoQ}^{2-}$ species. These are further reduced to $\mathrm{CoQ}^{4-}$ by receiving two electrons. Finally, one $\mathrm{CoQ}^{4-}$ can bind two $\mathrm{Ca}^{2+}$ ions, creating a $\mathrm{Ca}^{2+}-\mathrm{CoQ}^{4-}-\mathrm{Ca}^{2+}$ complex.

The complex formation between the reduced, deprotonated and charged 3,6-dihydroxy-2-methoxy-5-methyl-benzoquinone and $\mathrm{Ca}^{2+}$ cations can also be discussed in light of more general qualitative concepts [31]. While $\mathrm{Ca}^{2+}$ cations are defined as a s-LUMO Lewis acid, the anion of 3,6-dihydroxy-2-methoxy-5-methyl-benzoquinone with its high electron density can be classified as a strong $\pi$-Lewis base [30]. In general, certain metal ions (as hard Lewis acids) show a high affinity

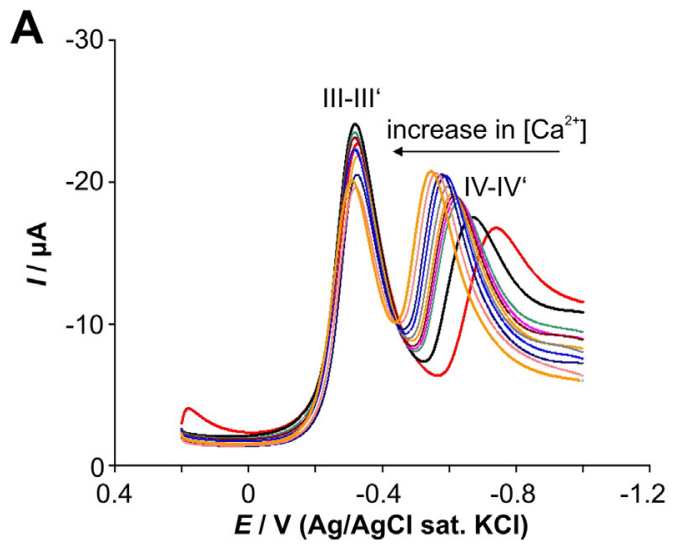

for oxygen donor ligands. Because the dihydroxy-anion form of compound 2 provides four electron donor sites it may easily form complexes with $\mathrm{Ca}^{2+}$ mainly via electrostatic interactions. Recently, a theoretical study has analyzed formation and stabilities of complexes of $\mathrm{Ca}^{2+}$ (and $\mathrm{Mg}^{2+}$ ) with several semi-orthoquinones confirming the general concept [32]. From the intercept of the dependence $E_{\mathrm{p}} \mathrm{vs} . \log \left[\mathrm{Ca}^{2+}\right]$ given in Fig. 5B, and using the thermodynamic formalism $[33,34]$ we estimate the stability constant between the reduced form of 3,6-dihydroxy-2-methoxy-5-methyl-benzoquinone and $\mathrm{Ca}^{2+}$ ions to be $8.5 \times 10^{7} \mathrm{~mol}^{-1} \mathrm{dm}^{3}$. This value is very close to the stability constant value of the 2,3-dihydroxyl derivative of Coenzyme $\mathrm{Q}-1$ and $\mathrm{Ca}^{2+}$ ions reported previously [19].

\subsection{Antioxidative potential of the hydroxyl derivatives of Coenzyme Q-0}

Recently we have demonstrated that the hydroxylated CoQ-1 and CoQ-10 derivatives [19], as well as the hydroxylated methoxy BQ [20], exhibit relatively strong antioxidative potentials. The increased antioxidant activity of the hydroxy derivatives of $\mathrm{CoQ}$ is caused by the increased electronic density introduced by $\mathrm{OH}$ groups, which are essential for the redox properties of these derivatives. Most of the evidence about the antioxidative potential of the hydroxy-CoQ-1 and CoQ-10 derivatives were obtained by EPR technique, using human monocyte cells as generators of reactive oxygen species [19,20]. In this work we offer a simple electrochemical approach to assess the antioxidative potential of the hydroxy-derivatives of the CoQ- 0 . The proposed method relies on the "electrocatalytic regenerative mechanism" [30,33], in which the electrochemically oxidized products of the redox active ABTS assay are converted (reduced) to their initial electroactive form by a chemical reaction with antioxidants (hydroxyl CoQ-0 derivatives in our case). Electrochemical oxidation of ABTS (2,2'-azino-bis(3-ethylbenzothiazoline-6-sulfonate)) at a glassy carbon electrode in neutral media is characterized by two reversible redox signals appearing in cyclic voltammograms (Fig. 6A). The first voltammetric pair of peaks corresponds to the creation of a stable radical cation of ABTS, the second oxidation step to formation of a di-cation of ABTS. Both signals in the cyclic voltammograms of ABTS can be described as one-electron diffusion controlled redox processes [35], because cyclic voltammograms of ABTS recorded at different scan rates show two well-defined peaks characterized by peak-to-peak separations of about $60 \mathrm{mV}$ (Fig. S7). The peak currents of both voltammetric peaks of ABTS depend linearly on the square root of the applied scan rates (not shown). While the mid-peak potential of the voltammetric peak at less positive potentials is almost insensitive to the scan rates, the mid-peak potential of the voltammetric peak at more positive potentials shifts slightly in positive direction (by about $10 \mathrm{mV}$ ) upon increasing scan rates from $2 \mathrm{mV} / \mathrm{s}$ to $50 \mathrm{mV} / \mathrm{s}$. The

B

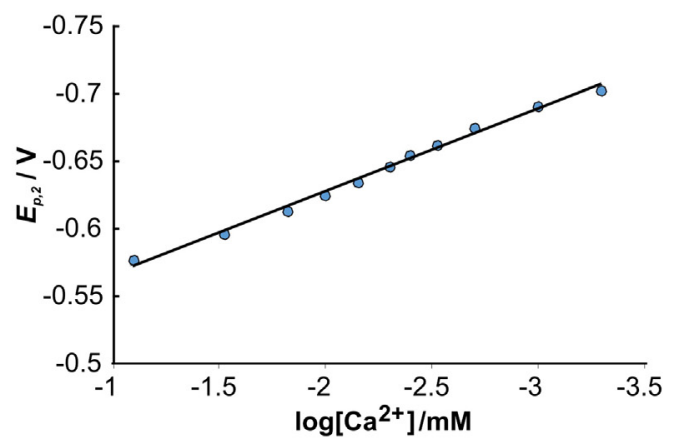

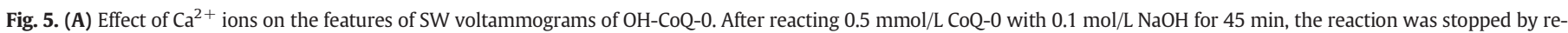

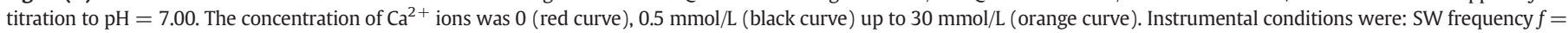

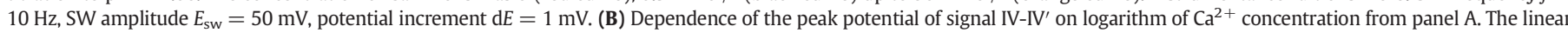

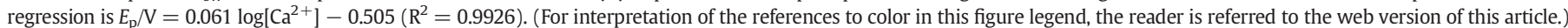


A

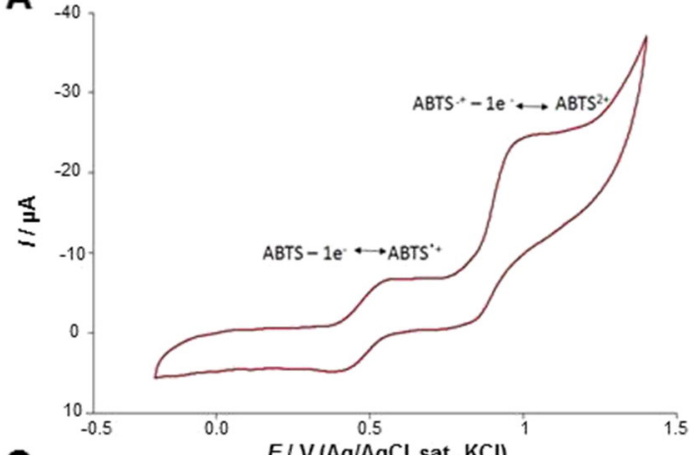

C

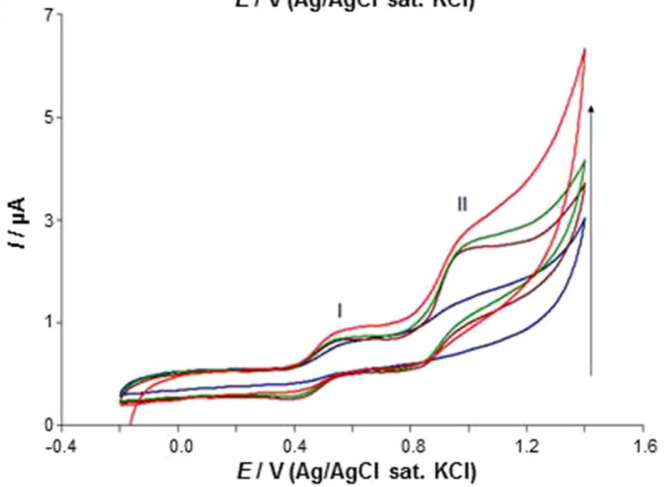

B

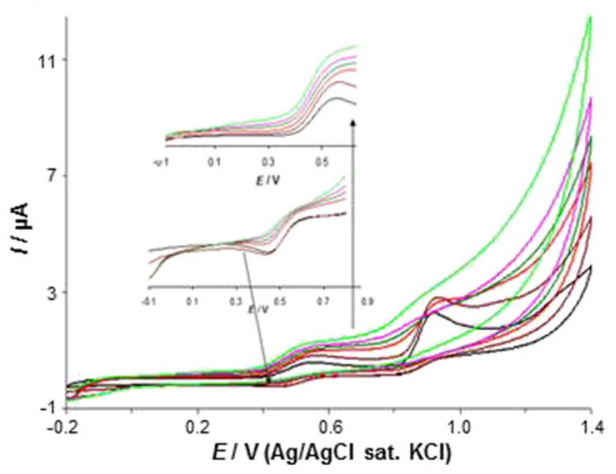

D

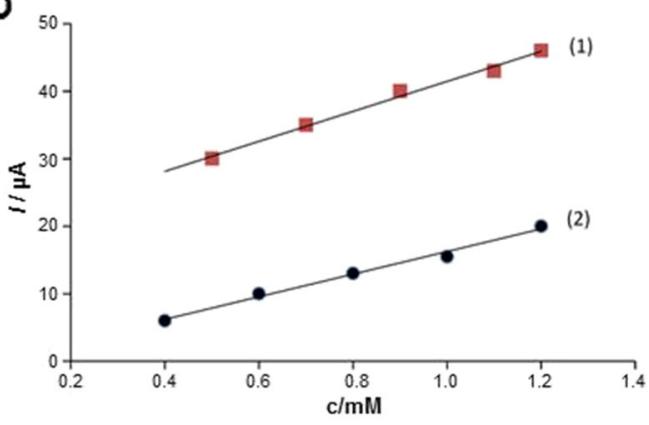

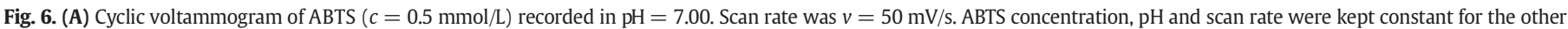

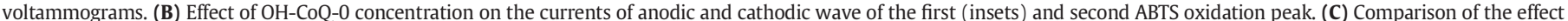

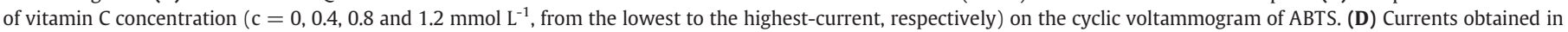

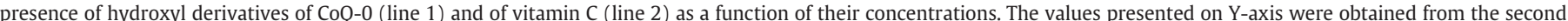

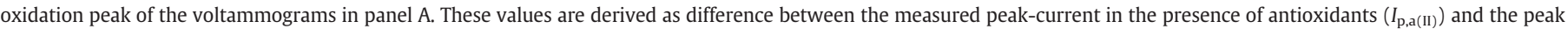
current measured in absence of antioxidants $\left(I_{\mathrm{p}, \mathrm{a}(\mathrm{II})(\mathrm{ABTS}) 0}\right)$. The slopes of the linear fits of (1) and (2) are $22.2 \mu \mathrm{A} \mathrm{L} / \mathrm{mmol}$ and $16.75 \mu \mathrm{A} \mathrm{L} / \mathrm{mmol}$, respectively.

diffusion coefficient of the ABTS species involved in the first and the second voltammetric peak were estimated from the slope of $I_{\mathrm{p}} v s . v^{0.5} \mathrm{de}-$ pendence resulting in values of $1.93 \cdot 10^{-6} \mathrm{~cm}^{2} \mathrm{~s}^{-1}$ and $2.2 \cdot 10^{-6} \mathrm{~cm}^{2} \mathrm{~s}$ 1 , respectively [33]. The kinetic rate constants of the electron transfers $\left(k_{\mathrm{s}}\right)$ of the first and the second step of ABTS electrode transformation were determined with the method proposed by Eisner and Gileadi [36] yielding $k_{\mathrm{s}, 1}=0.040 \mathrm{~cm} \mathrm{~s}^{-1}$ and $k_{\mathrm{s}, 2}=0.008 \mathrm{~cm} \mathrm{~s}^{-1}$ for the electron transfer steps.

In the presence of hydroxylated CoQ-0 derivatives, a gradual increase in the anodic currents of both peaks can be observed that is followed by a concomitant decrease of their cathodic peak currents (Fig. 6B, insets for first oxidation peak of ABTS). During the recording time of cyclic voltammograms, the oxidized products of the electrode reaction of ABTS undergo chemical reaction with the hydroxyl CoQ-0 derivatives present in the electrochemical cell. As the concentration of the hydroxyl CoQ-0 derivatives increases, an intermolecular electron transfer takes place between the $\mathrm{OH}-\mathrm{CoQ}-0$ derivatives and the electrode-generated oxidized forms of ABTS. The voltammetric features of this reaction are typical for an electrocatalytic regenerative $\mathrm{EC}^{\prime}$ mechanism [37]. The chemical reactions between the hydroxyl derivatives of CoQ-0 and the oxidized forms of ABTS can be presented by Schematic 3:

As a consequence of the intermolecular reaction between hydroxyl CoQ-0 derivatives and the oxidized forms of ABTS, the redox active reac$\operatorname{tant}(\mathrm{s})$ are regenerated in the electrode double layer for additional re-

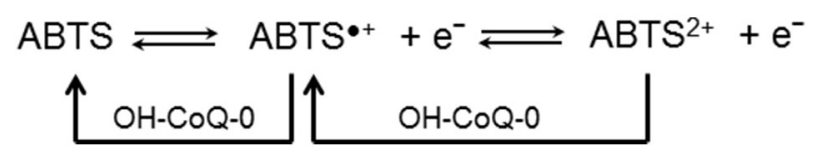

Schematic 3. Redox transformation of ABTS and $\mathrm{EC}^{\prime}$ mechanism in the presence of hydroxyl Coenzyme Q-0 (OH-CoQ-0) derivatives. oxidation within experiment time. These phenomena are characterized by a gradient peak-current increase in the cyclic voltammograms, as the concentration of the hydroxyl derivatives of CoQ-0 (the antioxidants) increases. In addition, the voltammograms are characterized by a current elevation of the post-Faradaic current regions, which is a typical feature of catalytic regenerative mechanisms $[33,37,38]$. Since no absolute determination of the antioxidative potential is possible with this method, we used vitamin $C$ to allow a comparison of the antioxidative ability of hydroxyl CoQ-0 derivatives relative to that of vitamin C. For that purpose, we performed an additional set of experiments in which we changed the concentration of vitamin $C$ in the electrochemical cell. The voltammetric outputs of these experiments (Fig. 6C) give linear dependences of the relative peak-current increase $v s$. the concentration of hydroxyl CoQ-0 or vitamin C (Fig. 6D). The slope is slightly higher for CoQ-0 which implies that the antioxidative potential of hydroxyl CoQ0 derivatives is slightly higher than that of vitamin $\mathrm{C}$.

\section{Conclusions}

In this work we have focused on the chemistry of the simplest member of ubiquinone family, i.e. the CoQ-0. Its redox chemistry was studied in buffered and non-buffered aqueous solutions with $\mathrm{pH}$ ranging from 1 to 10 with rather different voltammetric outputs. We found that only in buffered aqueous solutions the redox chemistry can be described by the common two electrons-two $\mathrm{H}^{+}$redox scheme. In non-buffered aqueous media, however, we observed three different voltammetric signals, which appear at distinct $\mathrm{pH}$. The features of those three signals reveal that the number of protons involved in the redox process of CoQ- 0 can vary from 0 to 2, depending on $\mathrm{pH}$ and on the ratio of proton concentration $v$ s. the initial CoQ- 0 concentration. The stabilization of the electrochemically generated anionic (hydroquinone-like) products obtained via reduction of CoQ- 0 occurs through hydrogen bonding with 
water molecules. In strong alkaline media above $\mathrm{pH}=12$, CoQ- 0 is not stable, since it reacts with the $\mathrm{OH}^{-}$anions, which leads to several hydroxylated derivatives. The chemistry of these CoQ-0 reactions was explored with electrochemical techniques, and also with HPLC-MS and EPR spectroscopy. We showed that the nature of the hydroxylated CoQ- 0 products depends on the $\mathrm{OH}^{-}$concentration and on the reaction time. One or both methoxy groups from the native structure of CoQ-0 can be cleaved in presence of $\mathrm{NaOH}$ at $\mathrm{pH} \geq 13$ and substituted by $\mathrm{OH}$ groups. Also, the non-substituted position 6 in the structure of CoQ-0 is susceptible to substitution with an $\mathrm{OH}$ group which is the only reaction found at $\mathrm{pH} 12$. Whenever both methoxy groups are cleaved, there is a high probability of obtaining benzoquinonic dimers. This reaction occurs either in strong alkaline environment ( $\mathrm{pH}>13$ ), or after extended reaction times of $\mathrm{CoQ}-0$ and $\mathrm{NaOH}$. The di-hydroxyl derivatives of CoQ- 0 , which are one of the products detected, have a strong potential to form stable complexes with $\mathrm{Ca}^{2+}$ ions. The importance of the hydroxylated CoQ-0 described in this work is quite intelligible, since some derivatives are recognized as a starting material and/or intermediates in the synthesis of CoQ-members $[2,4,39]$. Moreover, we have also shown that these hydroxyl derivatives of CoQ-0 have a very strong antioxidative potential comparable to that of Vitamin C. In the future, hydroxylated CoQ-0 compounds should be isolated to further facilitate their chemical analysis and to test their application as antioxidants or divalent cation chelators in biomedical systems.

\section{Acknowledgments}

R. G. and S. M. thank Goce Delčev University for providing funds for performing this work. I.B. acknowledges HOMFOR Excellent research grant by the Medical School, University of Saarland, the SFB 1027 project C4 and the DFG project BO3643/3-1, while M.H. acknowledges SFB 1027 A2 project and the DFG project HO2190/4-1.

\section{Appendix A. Supplementary data}

Supplementary data to this article can be found online at http://dx. doi.org/10.1016/j.bioelechem.2016.05.008.

\section{References}

[1] B.L. Trumpower, Function of Quinones in Energy Conserving Systems, Academic Press Inc., New York, 1982.

[2] E.R. Price, S.C. Johnson, Quinones: Occurrence, Medicinal Use and Physiological Importance, Nova Science Pub Inc., 2013

[3] H. Nohl, W. Jordan, R.J. Youngman, Quinones in Biology: Functions in Electron Transfer and Oxygen Activation, Adv. Free Radic. Biol. Med. 2 (1986) 211-279.

[4] J. Swenton, Chemistry of Quinones, John Wiley, New York, 1988.

[5] R.L. Lester, F.L. Crane, Y. Hatefi, Coenzyme Q-a new group of quinones, J. Am. Chem. Soc. 80 (1958) $4751-4752$.

[6] F.L. Crane, Biochemical functions of coenzyme Q10, J. Am. Coll. Nutr. 20 (2001) $591-598$.

[7] A. Roetig, E.-L. Appelkvist, V. Geromel, D. Chretien, N. Kadhom, P. Edery, M. Lebideau, G. Dallner, A. Munnich, L. Ernster, P. Rustin, Quinone-responsive multiple respiratory-chain dysfunction due to widespread coenzyme Q10 deficiency, Lancet 356 (2000) 391-395.

[8] H.P. Indo, H.-C. Yen, I. Nakanishi, K.-i. Matsumoto, M. Tamura, Y. Nagano, H. Matsui, O. Gusev, R. Cornette, T. Okuda, Y. Minamiyama, H. Ichikawa, S. Suenaga, M. Oki, T. Sato, T. Ozawa, D.K.S. Clair, H.J. Majima, A mitochondrial superoxide theory for oxidative stress diseases and aging, J. Clin. Biochem. Nutr. 56 (2015) 1-7.

[9] D. Abdali, S.E. Samson, A.K. Grover, How effective are antioxidant supplements in obesity and diabetes? Med. Princ. Pract. 24 (2015) 201-215.

[10] A.K.S.A. Mortensen, P. Dolliner, K.J. Filipiak, D. Pella, U. Alehagen, G. Steurer, G.P. Littarru, F. Rosenfeldt, Oral abstract session clinical: the effect of coenzyme Q10 on morbidity and mortality in chronic heart failure. Results from the Q-SYMBIO study, Eur. J. Heart Fail. 12 (2013) S20.
[11] N. Gueven, K. Woolley, J. Smith, Border between natural product and drug: comparison of the related benzoquinones idebenone and coenzyme Q10, Redox Biol. 4 (2015) 289-295.

[12] H.H. Szeto, L.P. James, A.J. Atkinson, Mitochondrial pharmacology: its future is now, Clin. Pharmacol. Ther. 96 (2014) 629-633.

[13] S. Jaber, B.M. Polster, Idebenone and neuroprotection: antioxidant, pro-oxidant, or electron carrier? J. Bioenerg. Biomembr. 47 (2014) 111-118.

[14] J. Wang, S. Li, T. Yang, J. Yang, Synthesis and antioxidant activities of Coenzyme Q analogues, Eur. J. Med. Chem. 86 (2014) 710-713.

[15] L.N. Laredj, F. Licitra, H.M. Puccio, The molecular genetics of coenzyme Q biosynthesis in health and disease, Biochimie 100 (2014) 78-87.

[16] H.M. Cocheme, G.F. Kelso, A.M. James, M.F. Ross, J. Trnka, T. Mahendiran, J. AsinCayuela, F.H. Blaikie, A.R. Manas, C.M. Porteous, V.J. Adlam, R.A. Smith, M.P. Murphy, Mitochondrial targeting of quinones: therapeutic implications, Mitochondrion 7 (Suppl.) (2007) S94-102.

[17] D. Graham, N.N. Huynh, C.A. Hamilton, E. Beattie, R.A.J. Smith, H.M. Cochemé, M.P. Murphy, A.F. Dominiczak, Mitochondria-targeted antioxidant mitoq10 improves endothelial function and attenuates cardiac hypertrophy, Hypertension 54 (2009) 322-328.

[18] A.M. James, R.A.J. Smith, M.P. Murphy, Antioxidant and prooxidant properties of mitochondrial Coenzyme Q Arch. Biochem. Biophys. 423 (2004) 47-56.

[19] I. Bogeski, R. Gulaboski, R. Kappl, V. Mirceski, M. Stefova, J. Petreska, M. Hoth, Calcium binding and transport by coenzyme Q J. Am. Chem. Soc. 133 (2011) 9293-9303.

[20] R. Gulaboski, I. Bogeski, V. Mirceski, S. Saul, B. Pasieka, H.H. Haeri, M. Stefova, J.P Stanoeva, S. Mitrev, M. Hoth, R. Kappl, Hydroxylated derivatives of dimethoxy1,4-benzoquinone as redox switchable earth-alkaline metal ligands and radical scavengers, Sci. Rep. 3 (2013).

[21] R. Petrucci, E. Giorgini, E. Damiani, P. Carloni, G. Marrosu, A. Trazza, G.P. Littarru, L. Greci, A study on the interactions between coenzyme $\mathrm{Q} 0$ and superoxide anion. Could ubiquinones mimic superoxide dismutase (SOD)? Res. Chem. Intermed. 26 (2000) 269-282.

[22] K. Takehara, H. Takemura, Y. Ide, S. Okayama, Electrochemical-behavior of ubiquinone and vitamin-K incorporated into normal-alkanethiol molecular assemblies on a gold electrode, J. Electroanal. Chem. 308 (1991) 345-350.

[23] M.D. Greaves, A. Niemz, V.M. Rotello, Control of one- versus two-electron reduction of ubiquinone via redox-dependent recognition [11], J. Am. Chem. Soc. 121 (1999) 266-267.

[24] G.J. Gordillo, D.J. Schiffrin, Redox properties of ubiquinone (Uq10) adsorbed on a mercury-electrode, J. Chem. Soc. Faraday Trans. 90 (1994) 1913-1922.

[25] G.J. Gordillo, D.J. Schiffrin, The electrochemistry of ubiquinone-10 in a phospholipid model membrane, Faraday Discuss., (2000) 89-107; (discussion 171-190).

[26] P.S. Guin, S. Das, P.C. Mandal, Electrochemical reduction of quinones in different media: a review, Int. J. Electrochem. 2011 (2011) 22.

[27] M. Quan, D. Sanchez, M.F. Wasylkiw, D.K. Smith, Voltammetry of quinones in unbuffered aqueous solution: reassessing the roles of proton transfer and hydrogen bonding in the aqueous electrochemistry of quinones, J. Am. Chem. Soc. 129 (2007) $12847-12856$.

[28] A.A. Franke, C.M. Morrison, J.L. Bakke, L.J. Custer, X. Li, R.V. Cooney, Coenzyme Q10 in human blood: native levels and determinants of oxidation during processing and storage, Free Radic. Biol. Med. 48 (2010) 1610-1617.

[29] O.S. Ksenzhek, S.A. Petrova, M.V. Kolodyazhny, Redox properties of ubiquinones in aqueous-solutions, Bioelectrochem. Bioenerg. 9 (1982) 167-174.

[30] R.H. Crabtree, The Organometallic Chemistry of the Transition Metals, sixth ed., 2014.

[31] R.G. Pearson, Hard and soft acids and bases, J. Am. Chem. Soc. 85 (1963) 3533-3539.

[32] M. Witwicki, J. Jezierska, DFT insight into o-semiquinone radicals and Ca2 + ion interaction: structure, $g$ tensor, and stability, Theor. Chem. Accounts 132 (2013).

[33] R.L. Compton, E, K.R. Ward, Understanding Voltammetry: Simulation of Electrode Processes, Imperial College Press, 2014.

[34] D.D. Deford, D.N. Hume, The determination of consecutive formation constants of complex ions from polarographic data, J. Am. Chem. Soc. 73 (1951) 5321-5322.

[35] V. Mirceski, R. Gulaboski, M. Lovric, I. Bogeski, R. Kappl, M. Hoth, Square-wave voltammetry: a review on the recent progress, Electroanalysis 25 (2013) 2411-2422.

[36] U. Eisner, E. Gileadi, Anodic oxidation of hydrazine and its derivatives. Part I. The oxidation of hydrazine on gold electrodes in acid solutions, J. Electroanal. Chem. 28 (1970) 81-92.

[37] R. Gulaboski, V. Mirceski, New aspects of the electrochemical-catalytic (EC') mechanism in square-wave voltammetry, Electrochim. Acta 167 (2015) 219-225.

[38] R. Gulaboski, V. Mirčeski, S. Mitrev, Development of a rapid and simple voltammetric method to determine total antioxidative capacity of edible oils, Food Chem. 138 (2013) 116-121.

[39] L.X. Xie, M. Ozeir, J.Y. Tang, J.Y. Chen, S.-K. Jaquinod, M. Fontecave, C.F. Clarke, F Pierrel, Overexpression of the Coq8 kinase in Saccharomyces cerevisiae coq null mutants allows for accumulation of diagnostic intermediates of the coenzyme Q6 biosynthetic pathway, J. Biol. Chem. 287 (2012) 23571-23581. 